ISSN 1112-9867

\title{
PHYTOCHEMICAL STUDY AND ANTIBACTERIAL ACTIVITY OF DIFFERENT EXTRACTS OF Pistacia lentiscus L COLLECTED FROM DAHRA REGION WEST OF ALGERIA
}

\author{
F. Missoun ${ }^{1 *}$, F. Bouabedelli ${ }^{1}$, E. Benhamimed ${ }^{1}$, A. Baghdad $^{2}$ and N. Djebli ${ }^{1}$ \\ ${ }^{1}$ Laboratory of Pharmacognosy and Api-Phytotherapy, University of Mostaganem, Algeria \\ ${ }^{2}$ Chemistry Department, University of Mostaganem, Algeria
}

Received: 20 September 2016 / Accepted: 14 April 2017 / Published online: 01May 2017

\begin{abstract}
The purpose of this study was to investigate the phytochemical proprieties, antioxidant and antibacterial activities of different extracts of Pistacia lentiscus on two pathogenic bacteria. The concentration of total phenols was analyzed using Folin-Ciocalteu's method. Exracts of plant were evaluated for their antimicrobial activities against Staphylococcus aureus and Esherichia coli using the agar disk diffusion method and the minimal inhibitory concentration. The phytochemical study revealed the presence of major bioactive chemical constituents in different extracts of $P$. lentiscus (flavonoids, alkaloids, saponins, tannins, terpenoids, glycosides and steroids). Results showed that this plant has antioxydant activity and high quantity of total phenols and flavonoids. Antibacterial activity of the aerial parts of $P$. lentiscus against tested bacteria has shown that Gram-negative strains were more resistant compared to the Gram- positive ones. We can conclude that Pistacia lentiscus from Dahra region under investigation can be a potential source of useful drugs.
\end{abstract}

Keywords: Pistacia lentiscus; Phytochemicals; total phenol; Flavonoids; Antibacterial activity.

Author Correspondence, e-mail: fatiha.missoun@yahoo.fr

doi: http://dx.doi.org/10.4314/jfas.v9i2.4 


\section{INTRODUCTION}

Infusions and decoctions of medicinal plants have long been used in traditional medicine to treat or prevent chronic diseases and to improve the quality of life [1-2]. Pistacia lentiscus L is a dioecious shrub belong to the Anacardiaceae family is originally from the Mediterranean region, Morocco and the Iberian Peninsula to the west and the south of France, Turkey, Iraq and Iran to the east, was grown in England since 1664 .It is mainly exported from Scio, the island where it was cultivated for centuries. The resin of Pistacia lentiscus L (mastic) has been used for over 2500 years in traditional Greek medicine to treat several diseases such as gastric pain and peptic ulcers [3]. Several scientific researches have justified the beneficial effect of Mastic to gastric diseases [4].

In Algeria Pistacia lentiscus is called darou and people have used mastic as a medicine for gastrointestinal ailments for several thousand years. Previous studies in Algeria have been done on Pistacia lentiscus extracts from the aerial part showed antimicrobial, antioxidant, hypotensive and hypoglycemic activities [5-9].

The fixed oil extracted from the fruit of Pistacia lentiscus in Constantine region east of Algeria is widely used especially to treat skin problems and respiratory conditions [10].

Infectious diseases caused by resistant microorganisms are associated with prolonged hospital stays, higher costs, and increased risk of morbidity and mortality [11-12].

However, providing new agents with new mechanisms of action is limited and emphasizes the need to develop new drug targets [13-14].

In this context, this work aims to study the phytochemistry and antioxydant activities of wide spread plant in Algeria Pistacia lentiscus and to investigate it's antibacterial activity on two bacteria notorious for their resistant to antibiotics.

\section{EXPERIMENTAL}

\subsection{Plant materials}

Leaves and stems of Pistacia lentiscus were collected randomly in 31 mars 2014 from Dahra region located North West chelef (Algeria).The samples collected were identified. The voucher specimens under code (Pl.D/3/2014) have been deposited at the Herbarium of the 
Laboratory of Pharmacognosy and Api-Phytotherapy (LPAP); University of Mostaganem, Algeria, for future reference.

The plant material was dried in dark area for few days and then passed in room temperature $\left(45-50 \mathrm{C}^{\circ}\right.$ ) for 24 hours. It was then finely grinded using a coffee grinder mill-type (for leaves and stems), to obtain a fine powder.

\subsubsection{Phytochemical screening}

Phytochemical analysis of different constituents which have a pharmacological interest was performed on the powdered samples using standard methods as described by [15-20]. Detecting the different phytochemical families that exist in the plant by precipitation reactions or staining using specific reagents to each family of compounds.

\subsubsection{Antioxidant activity}

The activity of free radicals was carried out by the use of 1,1-Diphenyl-2-picryl-hydrazyl (DPPH) according to Takao et al. (1994) [21].

The test on free radicals have been realised after an ascending Thin Layer Chromatography (TLC). The crude extract $(100 \mu \mathrm{g})$ of Pistacia lentiscus was melted down in methanol with 1 $\mathrm{mg} / \mathrm{ml}$ concentration and deposited on the plates (silica gel TLC is flat. DC Glasplatten kiselgel.2-25 micro $\mathrm{m}$, layer thickness $0.25 \mathrm{~mm}$, medium pore diameter $60 \AA$ ). The chromatograms are developed in butanol-acetic acid- distilled water mixture in the proportions 60-15-25 respectively; the plates were dried and sprayed with a solution of DPPH at $2 \mathrm{mg} / \mathrm{ml}$ of methanol. The active compounds appear as white or yellow spots on a purple background, after $30 \mathrm{~min}$ of reaction.

\subsubsection{Total phenolic content}

The powder (30 g) was put in ethanol $(80 \%, \mathrm{v} / \mathrm{v} ; 360 \mathrm{~mL})$ to macerate for $48 \mathrm{~h}$. and then filtrate with vacuum filtration, refrigerated for $24 \mathrm{~h}$ then decanted and concentrated under reduced pressure the crude extracts of aerial part of the plant, were used for our analyzes.

Total phenolic concentration was analyzed using Folin-Ciocalteu's method [22]. 0.125mL of the crude extract of the plant or gallic acide was added to $0.625 \mathrm{~mL}$ of Folin Ciocalteu. resting for $5 \mathrm{~min}, \quad 0.5 \mathrm{~mL}$ of sodium carbonate $(75 \mathrm{~g} / \mathrm{L})$ was added, the mixture was shaken and leave to rest for $2 \mathrm{~h}$. The absorbance of the samples was measured at $760 \mathrm{~nm}$ using 
UV-vis spectrophotometer. Concentrations were expressed as $\mathrm{mg}$ of gallic acid equivalent/g of lyophilized extract. The same procedure was used for making standard curve. All experiments were carried out in triplicates.

\subsubsection{Total flavonoids}

The aluminum chloride colorimetric method was used for mesure the total flavonoids concentrations [23] .Total flavonoids content was expressed as mg quercetin equivalents (mg $\mathrm{QE}) / \mathrm{g}$ extract.

\subsubsection{Thin Layer Chromatography}

Extracts of plant was melted in methanol with $1 \mathrm{mg} / \mathrm{ml}$ concentration. $10 \mu \mathrm{ml}$ of extracts were deposited on the analytical plates ( $2.5 \mathrm{~cm}$ above from the bottom) and dried on air for thirty minutes and kept in saturated developing chambers containing mobile phase and let run 3/4th of the height of the prepared plates [24] .There solvent system contains: Acetonitrilealcohol isopropylic-water-(1:1:3) (v/v/v). as mobile phase. The TLC was visualized under $\mathrm{UV}$ at $366 \mathrm{~nm}$, and the Rf were calculated.

\subsection{Tested microorganisms}

The antibacterial effect of plant was investigated on clinical bacterial strains and references, gram negative : Escherichia coli ATCC 25922 and gram positive : Staphylococcus aureus ATCC 29213, which are known to cause infections specially in urinary tract.

\subsubsection{Preparation of plant extracts for antibacterial test}

2.2.1.1. Percolation method: In this method the coffee press is used to drive steam of the active ingredients, $3 \mathrm{~g}$ of drug with $30 \mathrm{ml}$ of water (concentration 10\%). After 5 minutes at the temperature of about $100 \mathrm{C}^{\circ}$ (percolation through the coffee maker), we obtain a solution that was evaporated (in open air) then recovered with DMSO.

2.2.1.2. Extraction with methanol: flavonoids were extracted with methanol. $1 \mathrm{~g}$ of plant powder placed in a glass container (vial) with $10 \mathrm{ml}$ of $\mathrm{MeOH} 70 \%$, and then heated at $70 \mathrm{C} \circ$ for 5 minutes (This destroyed the plant tissue, preventing oxidation or enzymatic hydrolysis). The samples let macerate overnight (about 24 hours); after a first filtration on filter paper, and then evaporated (in the open air) and recovered with DMSO.

2.2.1.3. Infusion method: Boiling water with plant powder infused for 10 minutes, then 
filtered, and then evaporated (in the open air) and recovered with DMSO.

2.2.1.4. Decoction Method: Plants put in aerlenmeyer flask. Cover with cold water (10\% concentration) and bring to boil. Evaporated until reduced by about a third, filtred, and then evaporated again (in the open air) and recovered with DMSO.

\subsection{Antibacterial assay procedure}

\subsubsection{Inoculum preparation}

The inoculum is prepared from conserved colonies. Revived strains was taken and homogenized in $5 \mathrm{ml}$ of Mueller- Hinton broth and incubated for 3 to 5 hours at $37 \mathrm{C}^{\circ}$, inoculum was set to $10{ }^{5} \mathrm{CFU} / \mathrm{m} \mathrm{L} \mathrm{[25].}$

\subsubsection{The antimicrobial activities}

Agar disc diffusion method was used, the microorganisms were spread on MH agar plates by cotton swab ,sterilized disk (5mm) were soaked with $50 \mu 1$ of plants extracts $(10 \%)$. for the negative control the disks were soaked with sterilized water . Céphalexin (Lexin) $(100 \mathrm{mg} / \mathrm{ml})$ was the positive control and then incubated for $24 \mathrm{~h}$ at $37{ }^{0} \mathrm{C}$. The evaluation of the antimicrobial activities was by measuring the diameter of the inhibition zone

\subsubsection{Minimum Inhibitory Concentration (MIC) and Minimum Bactericidal Concentration (MBC) determination}

The minimum inhibitory concentration (MIC) is the lowest concentration of a substance that prevents visible growth of a bacterium [24]. For this test, various concentration of the stock $(100,50,25,12.5,6.25,3.12) \mathrm{mg} / \mathrm{ml}$ were tested against the tow microorganisms.

Extracts at different concentrations were added to Mueller Hinton broth to make up $1 \mathrm{ml}$ of solution than after $1 \mathrm{ml}$ of McFarland standard of each bacteria suspension $\left(10^{6} \mathrm{UFC} / \mathrm{ml}\right)$ was added .Tubes were incubated at $37{ }^{\circ} \mathrm{C}$ for 18-24 h. Tow control tubes were prepared, one containing the extract without the organism and the second containing the medium with the inoculum. The minimum bactericidal concentration (MBC) defined as the concentration those results in microbial death. This was done only on some extracts having high antimicrobial activity.

\section{RESULTS}

Phytochemical study showed that the plant Pistacia lentiscus L contained flavonoids, alkaloids, 
saponins, tannins, glycosides, terpenoids and steroids, and does not contain anthraquinons and quinons. Quantitative Analysis showed that this plant contained high quantity of flavonoids. Results revealed that total phenolic content in the extract of Pistacia lentiscus L was (114.95 \pm $12 \mathrm{mg}$ GAE/g DM), the concentration of flavonoids was $25.212 \pm 2.13 \mathrm{mg} \mathrm{EQ} / \mathrm{g}$ of extract (Table 2).

The methanolic extract of aerial parts was used to study the antioxidant activity. The use of methanol like solvent permits the extraction of phenolic compounds from the leaf and stem of P. lentiscus. The plant presented a better scavenging efficiency toward DPPH radical manifested in the TLC analysis UV light with yellow and white spot in purple background, The TLC analysis UV light of Pistacia lentiscus $L$ showed five spot ((Rf) = 0.04; 0.11;0.30; $0.41 ; 0.93)$.Extract in methanol confirms the presence of various group of phytochemicals (coumarins, xanthons, flavonols, phenolic acid and flavone) .Different retardation factors ( $R_{\mathrm{f}}$ )values of phytochemicals also reflect an idea about their polarity (figure 1).

Results of antibacterial activities of P. lentiscus against $S$. aureus and E. coli showed a remarkable antibacterial effect against gram positive strains $S$. aureus, the higher inhibitory activity was with decoction method with diameter $(25.5 \pm 0.5)$.However no inhibitory effect was noted with gram negative strains E. coli (table 3 and 4).

Results of MIC and MBC determination (Table 5) and the ratio of MBC/MIC (table 6) showed that $S$ aureus was more sensitive to different extracts of P. lentiscus, E coli was resistant to different extracts of this plant. 
Table 1. Phytochemicals screening of aerial of Pistacia lentiscus $L$

\begin{tabular}{llll}
\hline Extract constituents & leaves & \multicolumn{1}{l}{ Concentraction $(\mathbf{m} / \mathbf{g}$ of plant $)$} \\
\cline { 3 - 3 } Flavonoids & & Aerial part \\
Alkaloids & +++ & 0.223 \\
Glycosides & ++ & nd \\
Tannins & ++ & nd \\
Saponins & +++ & nd \\
Steroids & +++ & nd \\
terpenoids & and & ++ & nd \\
Quinons & & \\
Anthraquinons & - & nd \\
\hline
\end{tabular}

(- Absent,+ present,+++ present in high quantity ,nd not determined).

Table 2. Levels of total phenolic (mg of Gallic acid equivalent per $1 \mathrm{~g}$ lyophilized extract) and flavonoid contents (expressed as mg Quercetin equivalents/g extract contents in aqueous extract of Pistacia lentiscus $L$.

\begin{tabular}{|l|l|l|}
\hline species & Total phenolic (mg GAE/1g) & Total flavonoids (mg QE/ g) \\
\hline leaf and stem & $114.95 \pm 6.25$ & $25.212 \pm 2.13$ \\
\hline
\end{tabular}

Table 3. Effect of differents extracts of aerial parts of Pistacia lentiscus L microorganisms Against Staphylococcus aureus and Esherichia coli

\begin{tabular}{l|llll|l}
\hline \multirow{2}{*}{ Microorganisms } & \multicolumn{2}{|l}{ Aerial parts } & \multirow{2}{*}{ Cephalexin } \\
\cline { 2 - 5 } & P & M & I & D & \\
\hline Escherichia coli $\left(\mathbf{G}^{-}\right)$ & $6 \pm 0.7$ & $5 \pm 0.2$ & $5 \pm 0.1$ & $7 \pm 0.9$ & 56.5 \\
Staphylococcus aureus $\left(\mathbf{G}^{+}\right)$ & $14 \pm 1$ & $18 \pm 0.7$ & $16 \pm 0.5$ & $25.5 \pm 0.5$ & 33 \\
\hline
\end{tabular}

Disc diameter :5mm. P: percolation. M:extraction with methanol. I: infusion. D: decoction 

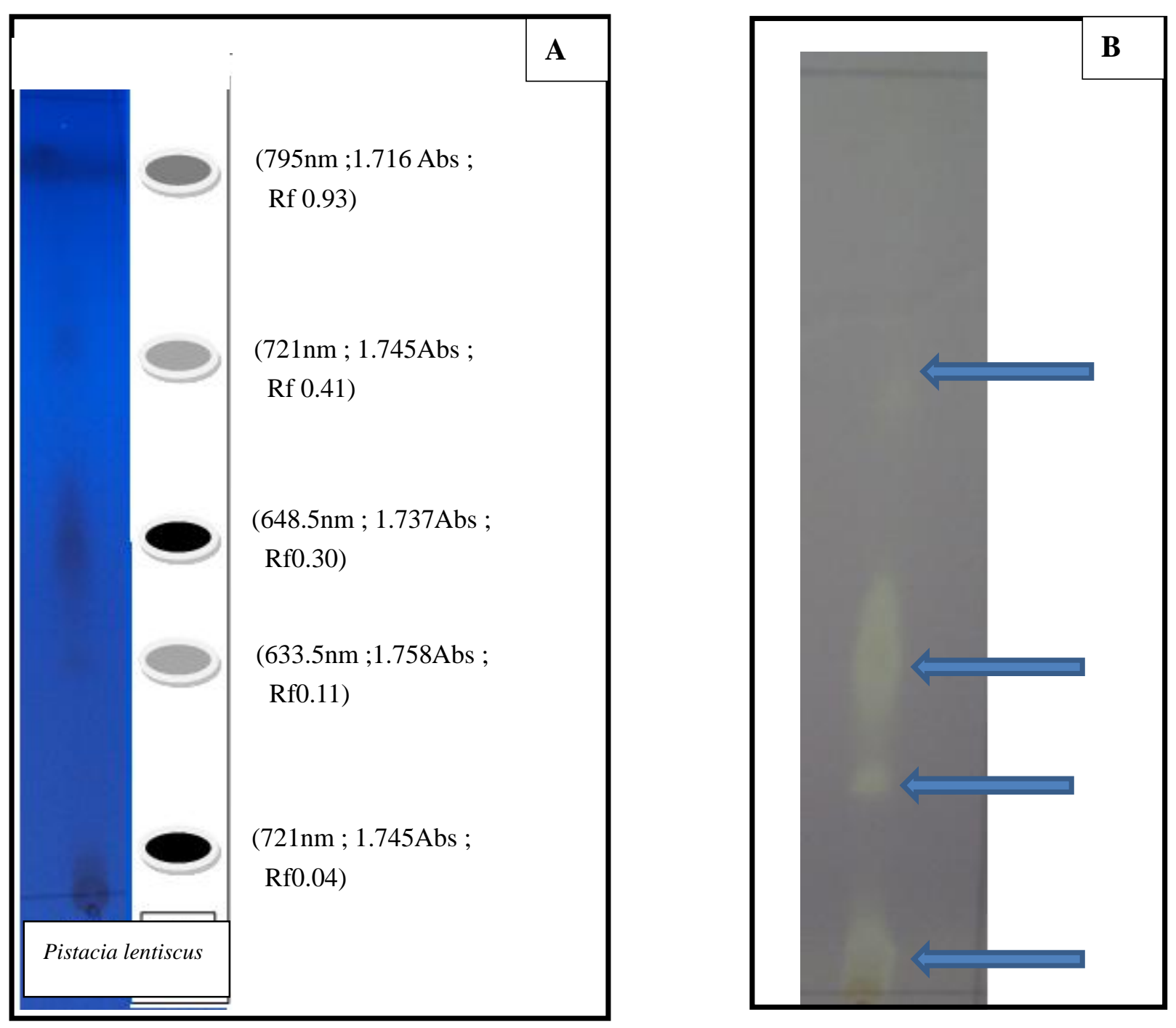

Fig.1. A: TLC profiles of contents of Pistacia lentiscus aerial part (UV $336 \mathrm{~nm}$ ).

B: TLC after spraying with a methanolic solution of DPPH at $2 \mathrm{mg} / \mathrm{ml}$; Pistacia lentiscus

$$
(\mathrm{Rf})=0.04 ; 0.11 ; 0.30 ; 0.41)
$$


Table 4 .The inhibitory effect of extracts of plant on 02 pathogenic strains (Staphylococcus aureus and Escherichia coli).

Method of extraction of Staphylococcus aureus

Escherichia coli

\section{Pistacia lentiscus}

$100 \mathrm{mg} / \mathrm{ml}$

Percolation


Extraction with methanol


Infusion
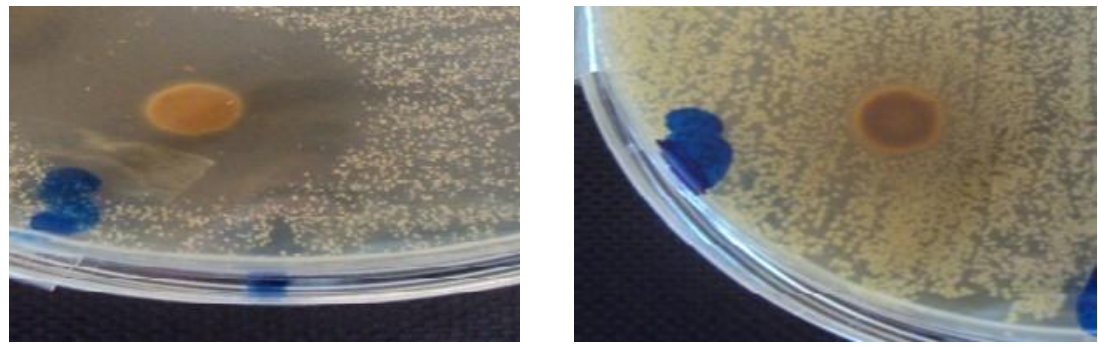

Decoction
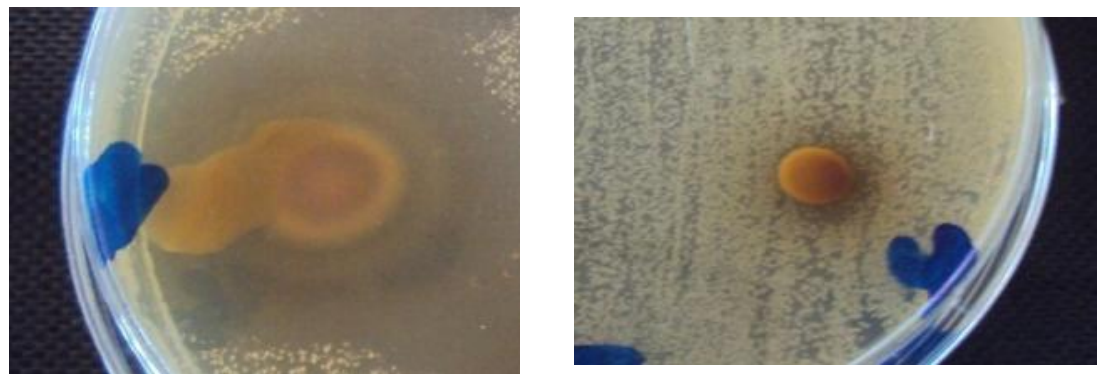

Cephalexin

(Lexin)

(100mg/ml)
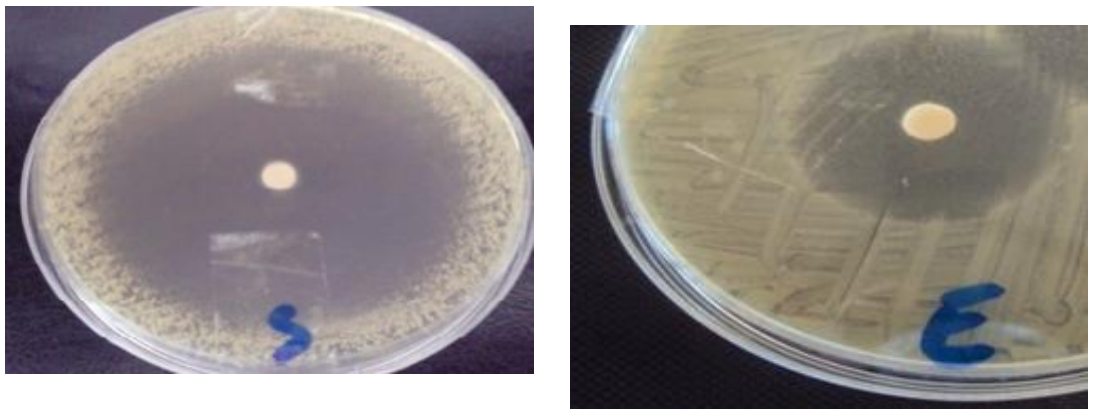
Table 5. Minimum Inhibitory Concentrations (mg/ml) and Minimum Bactericidal Concentration $(\mathrm{mg} / \mathrm{ml})$ of the different extracts

$\mathrm{CMI}$ and $\mathrm{CMB}(\mathrm{mg} / \mathrm{ml})$

\begin{tabular}{l|ll|l|l|l|l|l|l|l}
\multicolumn{1}{c}{} & \multicolumn{3}{c}{ Staphylococcus aureus } & \multicolumn{7}{c}{ Escherichia coli } \\
\cline { 2 - 10 } & & M & P & I & D & M & P & I & D \\
Pistacia & CMI & 50 & 50 & 50 & 50 & +100 & +100 & +100 & 50 \\
\cline { 2 - 11 } & CMB & 50 & 50 & 50 & 50 & +100 & +100 & +100 & 100
\end{tabular}

$\mathrm{CM}(\mathrm{mg} / \mathrm{ml})=100 ; \mathrm{C} 1=50 ; \mathrm{C} 2=25 ; \mathrm{C} 3=12.5 ; \mathrm{C} 4=6.25 ; \mathrm{C} 5=3.125,+100:$ resistant in $100 \mathrm{mg} / \mathrm{ml}$

Table 6.Ratio of CMB / CMI

\begin{tabular}{l|ll|lll|l}
\hline \multirow{2}{*}{ Aerial part } & method & \multicolumn{4}{|l}{ bactericidal activity } \\
& Staphylococcus aureus & \multicolumn{2}{l}{ Escherichia coli } \\
\multirow{2}{*}{ Pistacia } & Maceration & 1 & bactericidal & $\mathrm{R}$ & resistant \\
lentiscus & Percolation & 1 & bactericidal & $\mathrm{R}$ & resistant \\
& Infusion & 1 & bactericidal & $\mathrm{R}$ & resistant \\
& Decoction & 1 & bactericidal & 2 & bacteriostatic
\end{tabular}

MBC /MIC <2 :bactericidal; MBC /MIC > 2 : bacteriostatic; MBC /MIC 232 : resistant

\section{DISCUSSION}

Plants are a source of natural bioactive compounds with high medicinal activities for the treatment of various diseases [27].The use of plants for local remedies is a traditional custom .In Algeria the mastic tree is widespread in the forest belt.This study provides support to traditional and alternative use of $P$. lentiscus against various infections.

Phytochemical studies of P. lentiscus showed that the major components were flavonoids, alkaloids, saponins, tannins, glycosides, terpenoids and steroids, however the absence of anthraquinons and quinons. Our results are in agreement with many researches on Algerian $P$. lentiscus [8-28-29-30].

The TLC analysis UV light, allowed the identification of different metabolites of yellow and green (coumarins), orange (xanthons), [31]. Flavonols (yellow colours), phenolic acids (blue 
fluorescent), flavones (purple chestnut), [30] .The plant also exhibited a better scavenging efficiency toward DPPH radical.Our results are in agreement with those of [8-28-29] who found that P.lentiscus exhibited a great reducing power.

In a study realized by Rodriguez-Perez et al. (2013) [33], 46 phytochemical compounds were identified, 20 of which were identified for the first time in P. Lentiscus leaves. Flavonoids, phenolic acids and their derivatives were the most abundant compounds, those with the highest concentrations being myricetin glycoside, catechin, $\beta$-glucogallin, and quercitrin gallate.

The total phenolic concentration was $(114.95 \pm 6.25 \mathrm{mg}$ GAE/g of plant extract $)$ in the aerial parts of P. Lentiscus from Dahra region. Our results showed low concentrations of phenolic contents compared with others authors Zitouni et al (2016) [8], found that the Total phenolic concentration of P. Lentiscus from Nedroma region,west of Algeria were in leaves (216.289 \pm $20.62 \mathrm{mg} \mathrm{GAE} / \mathrm{g} \mathrm{DM})$ was significantly higher than those revealed in stems $(121.399 \pm 3.354$ $\mathrm{m} \mathrm{g} / \mathrm{g})$.

Comparing to others studies, the flavonoid contents in aerial parts of $P$. Lentiscus in this work were higher 25.212 \pm 2.13 (mg QE/ g) than their of Zitouni et al. (2016) [8], which found $19.162 \pm 0.436$ and $16.788 \pm 0.733 \mathrm{mg}$ QE/ $\mathrm{g}$ in leaves and stems ,respectively, and $12.93 \pm$ $1.69 \mathrm{mg} / \mathrm{g}$ found by Atmani et al (2011) [29] and $8.21 \pm 0.09 \mathrm{mg} / \mathrm{g}$ by Krimat et al ( 2014) [32].

Antimicrobial activities of the aerial parts (leaves and stems) of P. lentiscus against tested bacteria have shown that Gram-negative strains were more resistant compared to the Gram positive ones. Similar findings have been reported by other authors (Arab k et al. (2014)[35]; Benhammou N et al .(2007) [36]; Taoufik H et al. (2015)[37] who found that Gram positive strains were more sensitive to this plant than Gram negative strains. The higher inhibitory effect was with decoction method, Decoction involves first mashing and then boiling in water to extract oils, volatile organic compounds and other chemical substances as tannins that are stable to heat ,it is the traditional method that have been used since time in Algeria to treat many illness. Our results are in agreement with the results of bouabdelli et al. (2012) [9] who found that the decoction method had the highest antibacterial effect with $43.3 \%$, 
followed by percolation with $28.3 \%$,

Literature reports that for antimicrobial P. lentiscus has been observed that it has strong antifungal but low antibacterial activities. Pistacia lentiscus L. has found to be effective against Sarcinalutea, Staphylococcus aureus and E. coli and it also has antimycotic activity [38]. Results of MIC and MBC confirme the antibacterial results and showed that Staphylococcus aureus was more sensitive to this plant compared to E. coli which was more resistant to $P$. lentiscus extracted with different mode of extraction.

\section{CONCLUSION}

This work aims to investigate the phytochemical and antibacterial activities of Pistacia lentiscus L from Dahra region (Algeria). This study showed that Pistacia lentiscus is very rich on flavonoids, alkaloids, saponins, tannins, glycosides, terpenoids and steroids. Also this plant contained phenolic and flavonoids contents. The plant presented a better scavenging effectiveness toward DPPH radical .The antibacterial activities against $S$ aureus and E. coli prepared with four mode of extraction (percolation, maceration in methanol, decoction and infusion ) showed that Gram positive bacteria was more sensitive to the different extracts. The higher effect was noted with decoction method. Other research are required to isolate and identify the different phytochemical compounds from the crude plant extracts for proper drug development.

\section{ACKNOWLEDGEMENT}

Our research was funded by Science of Nature and Life Faculty. University of Mostaganem, Algeria.

\section{REFERENCES}

[1] Gonçalves S, Gomes D, Costa P, Romano A. The phenolic content and antioxidant activity of infusions from Mediterranean medicinal plants. Ind Crops Prod., 2013, 43(1): 465-471.

[2] Luo H, Li Q, Flower A, Lewith G, Liu J. Comparison of effectiveness and safety between granules and decoction of Chinese herbal medicine: A systematic review of randomized 
clinical trials. J Ethnopharmacol .,2012, 140(3): 555-567.

[3] Palevitch D, Yaniv Z. Medicinal Plants of the Holy Land. Modan Publishing House, Tel Aviv, Israel ., 2000.

[4] Bahman Fazeli-nasab . Ziba Fooladvand . Classification and Evaluation of medicinal plant and medicinal properties of mastic. Int J Adv Biol Biom Res., 2014; 2(6):2155-2161.

[5] Halima saiaha, Rachida allemb, Fatima zohra el kebira. Antioxidant and antibacterial activities of six Algerian medicinal plants. Int j pharm pharm sci, vol 8, issue 1., 367-374.

[6] Boulebda N, Belkhiri A, Belfadel F, Bensegueni A, Bahri L. Dermal Wound Healing Effect of Pistacia Lentiscus Fruit's Fatty Oil. Pharmacogn. Res., 2009, 1, 2, 6.

[7] Bendifallah L,benmahfoud A E, Hameni Y, Mameche,S. Phytochemical study and in vitro antimicrobial activity of Pistacia lentiscus L in boumerdes region (Algeria) .JFundam appl sci ., $2014,6(2) ; 229-237$.

[8] Zitouni Amel, Belyagoubi-Benhammou Nabila, Ghembaza Nacéra, Toul Fethi, AtikBekkara Fawzia. Antioxidant and antimicrobial activities of the Pistacia lentiscus and Pistacia atlantica extracts. African Journal of Pharmacy and Pharmacology Vol. 2(2). pp. 022-028, April., 2008.

[9] Bouabdelli F , Djelloul A , Kaid-Omar Z, Semmoud A, Addou A. Antimicrobial Activity of 22 Plants Used in Urolithiasis Medicine in Western Algeria. Asian Paicfic Journal of Tropical Disease., 2012 ,S530-S535.

[10] Abdeldjelil M. C., Bensegueni A., Messaï A, Agabou A, Benazzouz H. Medicinal use of Pistacia lentiscus fixed oil in Constantine province,north-east Algeria. J. Nat. Prod. Plant Resour., 2014, 4 (1):48-51.

[11] Akram M, Shahid M ,Khan A.U. Etiology and Antibiotics Resistance Pattern of Community Acquired Urinary Infections in J N M C Hospital Aligarh India. Ann. Clin. Microbiol. Antimicrob., 2007, 6, 4.

[12] Franklin D. Lowy . Antimicrobial resistance: the example of Staphylococcus aureus . J Clin Invest., 2003 May 1; 111(9): 1265-1273. doi: 10.1172/JCI200318535 .

[13] Projan SJ, Youngman PJ. Antimicrobials new solutions badly needed. Curr. Opin. Microbiol., 2002, 5:463-465. 
[14] a) Projan SJ. New (and not so new) antibacterial targets: from where and when will the novel drugs come?Curr. Opin. Pharmacol., 2002,2:513-522; b) Lanez T. and Hemmami H. Antioxidant Activities of N-ferrocenylmethyl-2- and -3-nitroaniline and Determination of their Binding Parameters with Superoxide Anion Radicals. Current Pharmaceutical Analysis, 2017, 13(2), 110 - 116; c) Lanez T. and M. Henni. Antioxidant activity and superoxide anion radical interaction with 2-(ferrocenylmethylamino) benzonitrile and 3-(ferrocenylmethylamino) benzonitrile J. Iran. Chem. Soc., 2016, 13 (9), 1741-1748.

[15] Harborne JB. Phytochemical methods. London: Chapman and Hall, Ltd 1973.

[16] Trease GE, Evans WC .pharmacognsy . 11 th ed. Brailliar Tiridel Can: Macmillian . 1989.

[17] Palici IB, Tina L, Ursica and Tina D. Method for Quantitative Determination of Polyphenolic Compounds and Tannins from Vegetal Products. Acta Universitatis Cibiniensis Seria F Chemia.,2005, 8(2):21-32.

[18] Ayoola GA, Coker HAB, Adesegun SA, Adepoju-Bello AA, Obaweya K,Ezennia EC, Atangbayila TO .Phytochemical screening and antioxidant activities of some selected medicinal plants used for malaria therapy in Southwestern Nigeria. Trop. J. Pharm. Res 2008; 7(3):1019-1024.

[19] Rebiai A., Lanez T., Belfar M.L., Int. J. Pharmacol. 2011, 7 (1), 113-118, doi: 10.3923/ijp.2011.113.118.

[20] a) Rebiai A., Lanez T., Belfar M.L. Total polyphenol contents, radical scavenging and cyclic voltammetry of Algerian propolis. Int J Pharm Pharm Sci, 2014, 6 (1), 395-400, b) Belfar ML., Lanez T., Rebiai A., Ghiaba Z. Evaluation of Antioxidant Capacity of Propolis Collected in Various Areas of Algeria Using Electrochemical Techniques. Int. J. Electrochem. Sci., (2015), 10, $9641-9651$

[21] Takao T , Futoshi Kitatani, Naoharu Watanabe, Akihito Yagi \& Kanzo Sakata .A Simple Screening Method for Antioxidants and Isolation of Several Antioxidants Produced by Marine Bacteria from Fish and Shellfish, Bioscience, Biotechnology, and Biochemistry., 1994. 58:10, 1780-1783, DOI: 10.1271/bbb.58.1780.

[22] Milliauskas M G, V enskutonis PR, van B eek TA. Screening of radical 
scavenging activity of some medicinal and aromatic.,2004; Food Chem., 85: 231-237.

[23] Zhishen J, Mengcheng T, Jianming W. The determination of flavonoid contents in mulberry and their scavenging effects on superoxide radicals. Food Chem ., 1999 64:555-9.

[24] Stahl E. Thin layer chromatography: A laboratory handbook. ; 2nd ed.. Softcover reprint of the original 2nd .,1969.

[25] Clinical and Laboratory Standards Institute. Performance standards for antimicrobial disk susceptibility tests. Wayne: Clinical and Laboratory Standards Institute., 2006 . [26] Moroh J.-L. A, Bahi C, Dje K., Loukou y. G., guede-Guina F. Antibacterial study of the activity of acétatique extract (EAC) Morindamorindoides (Baker) milne-redheat (rubiaceae) on in vitro growth of Escherichia coli strains, Bulletin of the Royal Society of Sciences of Liège, Vol. 77., 2008 , pp. 44 - 61.

[27] Sharma BC. In vitro antibacterial activity of certain folk medicinal plants from Darjeeling Himalayas used to treat microbial infections. Journal of Pharmacognosy and Phytochemistry .,2013,4:1-4.

[28] Atmani D, Chaher N, Berboucha M, Ayouni K, Lounis H, Boudaoud H, et al. Antioxidant Capacity and Phenol Content of Selected Algerian Medicinal Plants. Food Chemistry .,2009,112(2): 303-309.

[29] Atmani D, Chaher N, Ayouni K, Berboucha M. Antioxidant capacity of Pistacia lentiscus and Fraxinus angustifolia extracts and their fractions. Planta Med 2011; 77 (12):1407-1407.

[30] Benhammou N, Atik Bekkara F, Kadifkova P. Antiradical capacity of the phenolic compounds of Pistacia lentiscus L. and Pistacia atlantica Desf. Advances in Food Sciences., 2007, 29(3): 155-161.

[31] Ladigina E. Y., Safronich L. N., Otriacheva V. E., Balandina I. A., Grinkevich N. I., Sorokina A. A., Glizin V. I., Molodojnikova L. M., Mitin Y. S., Samilina I. A., Ermakova V. A., 1983. Chemical analysis of medicinal plants: $172 \mathrm{p}$.

[32] Dawson R., Elliott D., Elliott W., Jones K., Edition Mir, Moscou. Dictionnaire de biochimiste., 1991.

[33] Rodriguez-Perez C, Quirantes-Piné R, Amessis Ouchemoukh N, Madani K, Segura-Carretero A, Fernández-Gutierrez A. A metabolite-profiling approach allows the 
dentification of new compounds from Pistacia lentiscus leaves. Journal of Pharmaceutical and Biomedical Analysis .,2013, 77:167-174.

[34] Krimat S, Dob T, Lamari L, Boumeridja S, Chelghoum C, Metidji H. Antioxidant and antimicrobial activities of selected medicinal plants from Algeria. Journal of Coastal Life Medicine ., 2014, 2(6): 478-483.

[35] Arab K, Bouchenak O, Yahiaoui K. Phytochemical study and evaluation of the antimicrobial andantioxidant activity of essential oils and phenoliccompounds of Pistacia lentiscus 1. Journal ofFundamental and Applied Sciences ., 2014, 6(1), 79-93.

[36] Benhammou N, Atik Bekkara F, Kadifkova P. Antiradical capacity of the phenolic compounds of Pistacia lentiscus L. and Pistacia atlantica Desf. Advances in Food Sciences., 2007, 29(3): 155-161.

[37] Taoufik Haloui, Abdellah Farah, Mounyr Balouiri, Marwa Chraibi, Mouhcine Fadil, Kawtar Fikri Benbrahim, Aziz Belrhiti Alaoui.Bacteriostatic and Bactericidal Profile of Leaves and Twigs Essential oils of Moroccan Pistacia lentiscus L. J App Pharm Sci., 2015, 5 (06): 050-053.

[38] Magiatis P, Melliou E, Sounis ALS, Chinou BI, Mitaku S. Chemical composition and antimicrobial activity of the essential oil of Pistacia lentiscus var. chia. Planta medica., 1999, 65(8); 749-752.

\section{How to cite this article:}

Missoun F, Bouabedelli F, Benhamimed E, Baghdad A, Djebli N. Phytochemical study and antibacterial activity of different extracts of Pistacia lentiscus L collected from Dahra region west of Algeria .. J. Fundam. Appl. Sci., 2017, 9(2), 669-684. 